\title{
Inhibition of CD147 gene expression via RNA interference reduces tumor cell invasion, tumorigenicity and increases chemosensitivity to cisplatin in laryngeal carcinoma Hep2 cells
}

\author{
CHAN ZHU ${ }^{1,2 *}$, YUQIN PAN ${ }^{2 *}$, BANGSHUN HE $^{2}$, BO WANG ${ }^{1,2}$, YONGFEI XU ${ }^{1,2}$, \\ ${\text { LILI } \mathrm{QU}^{2} \text {, } \text { QIAN BAO }^{1,2} \text {, FULIANG TIAN }}^{1,2}$ and SHUKUI WANG ${ }^{1,2}$ \\ ${ }^{1}$ Department of Life Sciences, Nanjing Normal University, Nanjing, Jiangsu $210046 ;{ }^{2}$ Central Laboratory of \\ Nanjing First Hospital Affiliated to Nanjing Medical University, Nanjing, Jiangsu 210012, P.R. China
}

Received September 8, 2010; Accepted November 1, 2010

DOI: $10.3892 /$ or.2010.1088

\begin{abstract}
CD147, also named extracelluar matrix metalloproteinase inducer (EMMPRIN), is a member of the immunoglobulin family and a glycoprotein enriched on the surface of tumor cells, which promotes invasion, metastasis, growth and survival of malignant cells, and is known to confer resistance to some chemotherapeutic drugs. To determine the possible role of CD147 in the invasive properties of laryngeal carcinoma, we used an RNA interference approach to silence CD147 expression in the Hep2 cell line at high levels of CD147 expression. Our results showed that CD147 expression was significantly impeded at both mRNA and protein levels, which resulted in a decrease of the Hep2 invasion activity in vitro and tumorigenicity in nude mice. The suppression of CD147 expression also sensitized cells to cisplatin. Our current results indicated that CD147 was a laryngeal carcinoma-related gene and CD147 might be a potential target for therapeutic anti-cancer drugs.
\end{abstract}

\section{Introduction}

Laryngeal carcinoma is the 11th commonest form of cancer in men worldwide, with 121,000 new cases in 1985 (1). It is one of the most common malignancies in Europe, with about

Correspondence to: Dr Shukui Wang, Central Laboratory of Nanjing First Hospital Affiliated to Nanjing Medical University, Nanjing, Jiangsu 210012, P.R. China

E-mail: shukwang@163.com

${ }^{*}$ Contributed equally

Abbreviations: EMMPRIN, extracelluar matrix metalloproteinase inducer; MMPs, matrix metalloproteinase; RNAi, RNA interference; shRNA, short hairpin RNAs; siRNA, small interfering RNA; VEGF, vascular endothelial growth factor

Key words: CD147, RNA interference, chemosensitivity, laryngeal carcinoma
52,000 new cases per year (2), approximately 9,500-11,000 new cases of laryngeal cancer are estimated to occur yearly in the United States $(3,4)$. It is also very common in the northeast of China in recent years, and has shown increasing tendency (5). Laryngeal carcinoma especially at late-stage is associated with high morbidity and poor long-term survival due to the absence of effective treatment methods. Thus, better understanding of molecular mechanisms underlying proliferation, invasion and survival of laryngeal carcinoma is critical for the development of optimal therapeutic modalities. Recent studies suggest that CD147 is highly expressed in laryngeal carcinomas $(6,7)$.

CD147 (also known as EMMPRIN, basigin, M6 and tumor cell derived collagenase stimulatory factor), a highly glycosylated transmembrane protein that belongs to the immunoglobulin superfamily (8), is widely expressed and enriched on the surface of many malignant tumor cells. These cancers include breast cancer, lymphoma, oral squamous cell carcinoma, glioma, melanoma, lung, and bladder and kidney carcinomas (9-11). CD147 plays an important role in tumor formation and invasion/metastasis in both animal models (12) and cancer patients (13).

The metastatic potential of cancerous cells is dependent upon their ability to disengage themselves from environmental cues that serve to regulate and constrain them. CD147 is found overexpressed in a number of cancerous specimens, coupled with its ability to induce matrix metalloproteinase (MMPs) expression (14). MMPs are a family of zincdependent endopeptidases which currently consists of more than 25 members. According to sequence homologies and related substrate preferences, MMPs can be divided into 5 subfamilies, collagenases, gelatinases, tromelysins, membrane-type MMPs, and others. MMPs expression allows degradation of the basement membrane that are believed to affect tumor angiogenesis, lymphangiogenesis, tumor growth, local invasion and subsequent distant metastasis (15).

Expression of CD147 was associated with poor prognosis, higher tumor grade, increased tumor size, and a higher mitotic index (13). Overexpression of CD147 is shown to promote tumorigenicity, invasion, and metastasis of malignant cells (16). Human breast cancer cells transfected with an CD147 expression vector showed increased tumorigenicity and 
Table I. The sequences of the designed CD147 specific shRNAs.

\begin{tabular}{ll}
\hline shRNA & \multicolumn{1}{c}{ Sequence } \\
\hline shRNA-control & 5'-GATCCACTACCGTTGTTATAGGTGTTCAAGAGACACCTATAACAACGGTAGTTTTTTTGGAAA-3' \\
& 5'-AGCTTTTCCAAAAAAACTACCGTTGTTATAGGTGTCTCTTGAACACCTATAACAACGGTAGTG-3' \\
shRNA1 & 5'-GATCCGCGGAGTTCAAGGTGGACTCTTCAAGAGAGAGTCCACCTTGAACTCCGTTTTTTGGAAA-3' \\
& 5'-AGCTTTTCCAAAAAACGGAGTTCAAGGTGGACTCTCTCTTGAAGAGTCCACCTTGAACTCCGCG-3' \\
shRNA2 & 5'-GATCCGTGACAAAGGCAAGAACGTCTTCAAGAGAGACGTTCTTGCCTTTGTCATTTTTTGGAAA-3' \\
& 5'-AGCTTTTCCAAAAAATGACAAAGGCAAGAACGTCTCTCTTGAAGACGTTCTTGCCTTTGTCACG-3'
\end{tabular}

invasive potential in mice (12). Down-regulation of CD147 expression by the antisense RNA decreases the secretions of MMP-2, MMP-9, vascular endothelial growth factor (VEGF) and the invasive ability of human glioblastoma cells (17). Moreover, CD147 was shown to serve as a receptor for extracellular cyclophilins (18), and link with caveolin-1 expression (19).

Hanata et al previously showed that CD147 was highly expressed in Hep2 cells (7). We used RNA interference (RNAi) technology to knock down the expression of CD147 in Hep2 cells to explore the role and mechanisms of CD147 in the progression of laryngeal carcinoma. The knockdown of CD147 expression reduce proliferative, invasive, angiogenic, and metastatic potential of transfected Hep2 cells both in vitro and in vivo. Furthermore, it increased the cancer cell chemosensitivity to cisplatin. All these results confirmed that CD147 was involved in laryngeal carcinoma development or progression and the RNAi of CD147 might increase sensitivity to cisplatin and might be an adjuvant gene therapy strategy to chemotherapy.

\section{Materials and methods}

Cell culture and animals. Hep2 cells, a human laryngeal carcinoma cell line (provided by the Chinese Academy of Sciences, Shanghai, China) was cultured in RPMI-1640 medium supplemented with $10 \%$ newborn carf serum (Gibco) at $37^{\circ} \mathrm{C}$ in a humidified atmosphere containing $5 \%$ $\mathrm{CO}_{2}$. BALB/c nude mice (males and 4 weeks old) were obtained from Center for Comparative medical Research of Yangzhou Uiversity.

Construction of shRNA expression vectors. The vector pSilencer 3.1-H1 neo (Ambion) was used to generate short hairpin RNA (shRNA) specific for CD147. Two different regions of CD147 mRNA were selected as the RNAi target sites: $370-390$ bp and $808-828$ bp (20). Two pairs of template oligonucleotides, each encoding one of the target sequences were designed and synthesized (designated as CD147 shRNA1 and CD147shRNA2 respectively), and another pair of oligonucleotides (designated as shRNA-control) encoding a non-specific shRNA used as a negative control was also synthesized (Table I). These oligonucleotides were annealed and subcloned into the HindIII and BamI sites of the vector according to the manufacturer's instructions. These recombinant vectors were designated as pSilencer-shRNA-control,
pSilencer-shRNA1 and pSilencer-shRNA2. They were sequenced for correct ligation.

Transfection of cells. Hep2 cells were plated in 6-well plates at a density of $3 \times 10^{5}$ cells per well and incubated overnight. Cells were transfected with pSilencer-shRNA1, pSilencershRNA2 and pSilencer-shRNA-control respectively using Lipofectamine 2000 (Invitrogen) according to the manufacturer's instructions. Forty-eight hours after transfection, Hep2 cells were diluted to 1:10 for passage and neomycin resistance clones were selected in the medium containing $500 \mu \mathrm{g} / \mathrm{ml} \mathrm{G} 418$ (Gibco) for 2 weeks. The positive clones were picked and expanded to establish cell lines. The stable transfection cell clones, designated as Hep2/shRNA1, Hep2/shRNA2 and Hep2/shRNA-control, were verified by quantitative real-time RT-PCR and Western blot analysis.

Quantitative real-time RT-PCR assays. Total cellular RNA of Hep2 cells were extracted using TRIzol reagent (Invitrogen). RNA integrity was confirmed by electrophoresis on ethidium bromide-stained 1\% agarose gel. The primer sequences used were for CD147: (sense) 5'-CCATGCTGGTCTGCAAGTC AG-3' and (antisense) 5'-CCGTTCATGAGGGCCTTGTC-3'; ß-actin (sense) 5'-CTGGAACGGTGAAGGTGACA-3' and (antisense) 5'-AAGGGACTTCCTGTAACAACGCA-3'. The mRNA level for CD147 was analyzed by one-step realtime reverse transcriptase polymerase chain reaction with RNA-direct ${ }^{\mathrm{TM}}$ SYBR-Green Real-time PCR Master Mix (Toyobo) according to the manufacturer's instructions. Cycling conditions were: $90^{\circ} \mathrm{C}$ for $30 \mathrm{sec}, 61^{\circ} \mathrm{C}$ for $20 \mathrm{~min}, 95^{\circ} \mathrm{C}$ for $60 \mathrm{sec}$, then 40 cycles at $95^{\circ} \mathrm{C}$ for $15 \mathrm{sec}, 60^{\circ} \mathrm{C}$ for $1 \mathrm{~min}$. The mRNA level for CD147 of each sample was normalized to that of the $\beta$-actin mRNA. The amplification was monitored on an ABI prism 7500 real-time PCR apparatus (ABI).

Western blot analysis. Cells were harvested from flasks, and lysed with ice-cold lysis buffer (50 mM Tris- $\mathrm{HCl}, \mathrm{pH} 7.4$, $150 \mathrm{mM} \mathrm{NaCl}, 1 \mathrm{mM} \mathrm{MgCl}{ }_{2}, 100 \mu \mathrm{g} / \mathrm{ml} \mathrm{PMSF}$ and $1 \%$ Triton X-100) for $30 \mathrm{~min}$ on ice. Cell lysates were then collected after centrifugation at $12,000 \mathrm{rpm}$ for $5 \mathrm{~min}$ at $4^{\circ} \mathrm{C}$. Equal amounts $(50 \mu \mathrm{g})$ of lysate proteins were separated on $10 \%$ SDS-PAGE gels, and transblotted onto PVDF membrane (Pall Corporation). After blocking with 5\% nonfat dry milk in TBST buffer (10 mM Tris, $\mathrm{pH} 7.5,150 \mathrm{mM}$ $\mathrm{NaCl}$, and $0.05 \%$ Tween-20) for $2 \mathrm{~h}$ at room temperature, the membrane was probed with 1:500 dilution of anti-CD147 
A

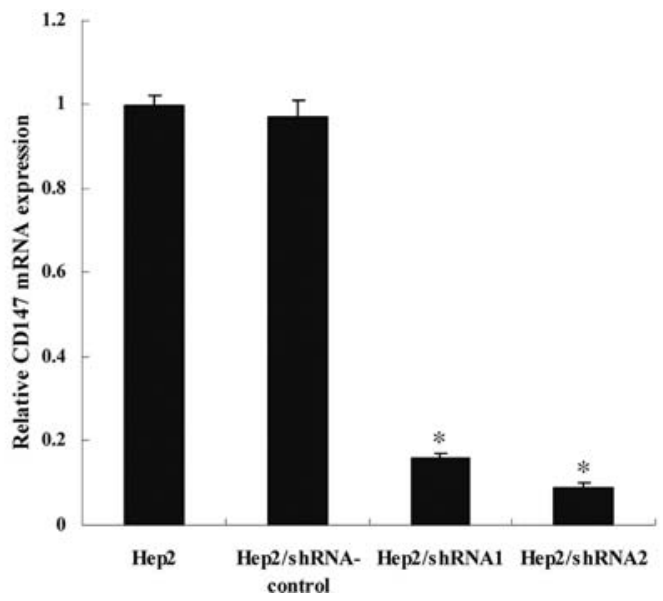

B

$\begin{array}{llll}\text { L1 } & \text { L2 } & \text { L3 } & \text { L4 }\end{array}$

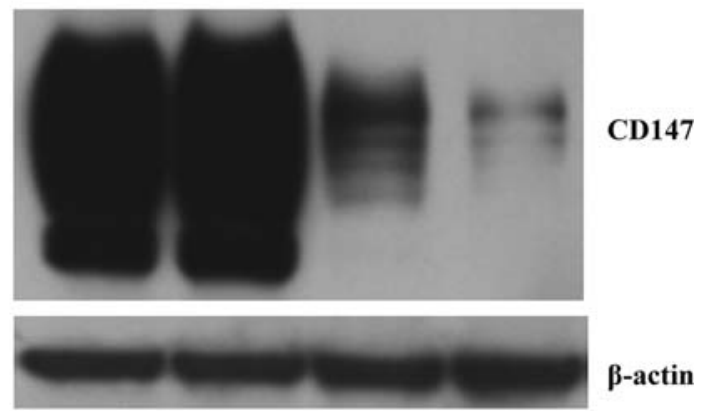

L1:Hep2

L2:Hep2/shRNA-control

L3:Hep2/shRNA1 L4: Hep2/shRNA2

Figure 1. CD147 specific shRNAs results in the reduction of CD147 mRNA and protein levels in Hep2 cells. (A) Relative mRNA levels were analysed by quantitative RT-PCR. B-actin was used as normalization control. " $\mathrm{P}<0.01$ compared with Hep2. (B) Western blot analysis of CD147 protein expressions. B-actin was used as loading control.

(Santa Cruz) and anti- $\beta$-actin (Santa Cruz) antibodies at room temperature for $2 \mathrm{~h}$, followed by incubation in a 1:2000 dilution of secondary antibodies conjugated to horseradish peroxidase (Santa Cruz) for $1 \mathrm{~h}$ at room temperature. Protein bands were detected using ECL detection system (Boster, China). All of the Western blot analyses were performed at least three times.

Cell proliferation assay. Cell proliferation in vitro was analyzed with 3-(4,5-dimethylthiazol-2-yl)-2,5-diphenyltetra zolium bromide (MTT). Briefly, 2,000 cells of each group were plated per well in three 96-well microplates in $200 \mu 1$ of medium. After 24, 48, 72, 96, $120 \mathrm{~h}$ of culture respectively, $20 \mu \mathrm{l}$ of MTT substrate $(5 \mathrm{mg} / \mathrm{ml}$ in PBS) was added to each well, and the plates were returned to standard tissue incubator conditions for an additional $6 \mathrm{~h}$. The medium was then removed, the cells were solubilized in $150 \mu \mathrm{l}$ of dimethyl sulfoxide, and colorimetric analysis was performed (wavelength, $490 \mathrm{~nm}$ ). Each experiment was done in triplicate.

Gelatin zymography. Protein concentrations in conditioned medium were determined using the bicinchonic acid method (BCA Kit, Pierce, USA). The gelatinolytic activities of MMP-2 and MMP-9 in the conditioned medium were assayed by electrophoresis on $10 \%$ polyacrylamide gels containing $1 \mathrm{mg} / \mathrm{ml}$ gelatin at $4^{\circ} \mathrm{C}$. PAGE gels were run at $120 \mathrm{~V}$, washed in $2.5 \%$ Triton $\mathrm{X}-100$ for $1 \mathrm{~h}$, and then incubated for $20 \mathrm{~h}$ at $37^{\circ} \mathrm{C}$ in activation buffer $(50 \mathrm{mM}$ Tris- $\mathrm{HCl}, \mathrm{pH} 7.5,5 \mathrm{mM}$ $\mathrm{CaCl}_{2}, 0.02 \%$ Brij-35). After staining with Coomassie Blue (10\% glacial acetic acid, $30 \%$ methanol and $0.5 \%$ Coomassie Blue) for $3 \mathrm{~h}$, the gel was destained with a solution of $10 \%$ glacial acetic acid, and $50 \%$ methanol without Coomassie Blue for $1 \mathrm{~h}$. White lysis zones indicating gelatin degradation were revealed by staining with Coomassie Blue R-250.

Invasion assay. Appropriate Matrigel (Becton-Dickinson) was added to the upper chamber of the transwell apparatus with $8-\mu \mathrm{m}$ pore size membrane (Costar). After the Matrigel solidified at $37^{\circ} \mathrm{C}, 3 \times 10^{5}$ cells were seeded onto the Matrigel and incubated at $37^{\circ} \mathrm{C}$ for $24 \mathrm{~h}$. Membranes coated with
Matrigel were swabbed with a cotton swab and fixed with $100 \%$ methanol for $10 \mathrm{~min}$. The membrane with cells were soaked in $0.1 \%$ crystal violet for $10 \mathrm{~min}$ and then washed with distilled water. The number of cells attached to the lower surface of the polycarbonate filter was counted at x400 magnification under a light microscope. Results were expressed as mean of triplicate experiments.

Drug sensitivity assay. To assess the chemosensitivity to anti-tumor drug cisplatin, the cells were seeded in triplicates on 96-well plates at $1 \times 10^{4}$ cells/well and incubated for $24 \mathrm{~h}$. The medium was then removed and replaced with fresh medium containing cisplatin (Sigma) with varying concentrations: $0.2,2$ and $20 \mu \mathrm{M}$. After $48 \mathrm{~h}$, cells were treated with MTT as described earlier. The inhibition ratio was calculated as $\left[A_{490 \text { (cisplatin+) }} / A_{490 \text { (cispatin-) }}\right]$. The assay was repeated three times.

In vivo tumor progression assay. All protocols involving animals were reviewed and approved by the ethics review committee of in the Animal Experimental Center of Nanjing First Hospital. We used 4- to 6-week old male BALB/c nude mice (Center for Comparative Medical Research of Yangzhou University, Yangzhou, Jiangsu, China). Tumor cells harvested with trypsin, washed with RPMI-1640, and resuspended in serum-free DMEM were subcutaneously inoculated $\left(5 \times 10^{6} /\right.$ $0.2 \mathrm{ml}$ ) into the right axillary fossa. The size of the transplanted tumors was measured every 4 days and the tumor volume was calculated using the formula $\mathrm{V}=1 / 2 \mathrm{x}\left(\mathrm{LxW}^{2}\right)$. The mice were sacrificed 28 days post-inoculation. Harvested tissues were fixed in $10 \%$ buffered formalin, embedded in paraffin, sectioned at $4 \mu \mathrm{m}$, and stained with $\mathrm{H} \& \mathrm{E}$, and immunohistochemistry analysis was used to detect CD147 protein expression. Goat anti-mouse CD147 polyclonal antibody (1:50 dilution, Santa Cruz Biotechnology) was used in standard indirect immunoperoxidase procedures.

Statistical analysis. SPSS17.0 software was used. Each assay was performed at least three times. The data were expressed as mean \pm SD and Student's t-test was used to determine the 


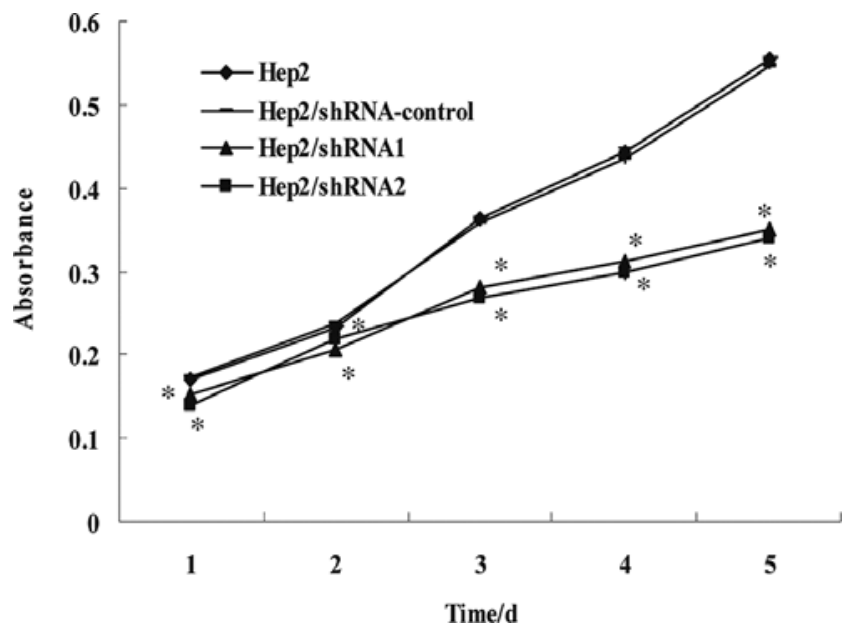

Figure 2. Proliferation of Hep2 cells stably expressing shRNA. Proliferation of Hep2 cells stably transfected with blank control (Hep2), pSilencerCD147shRNA-control, pSilencer-CD147 shRNA1 and pSilencer-CD147 shRNA2 were analyzed by MTT assay as described earlier. Spectrometrics absorbance at $490 \mathrm{~nm}$ was measured using a microplate reader. Each group contained three wells. ${ }^{*} \mathrm{P}<0.01$ compared with Hep2. significance of differences in multiple comparisons. $\mathrm{P}<0.05$ was considered to be statistically significant.

\section{Results}

The vector stably expressing CD147 shRNA causes effective and specific down-regulation of CD147 expression. The knock-down efficiencies of different CD147 specific shRNAs in Hep2 cells were first evaluated using real-time-PCR. Relative CD147 mRNA levels in individual stable transfectants were normalized against mRNA levels of an internal control gene, B-actin. As shown in Fig. 1A, cells transfected with pSilencer-CD147shRNA1 and pSilencer-CD147 shRNA2 both showed a significantly reduced transcription of CD147 mRNA when compared with that of vector control and control transfectants, respectively.

In addition, Western blot analysis (Fig. 1B) showed a reduced expression of CD147 protein in the same Hep2 cells transfected with pSilencer-CD147shRNA1 and pSilencerCD147shRNA2. The above results demonstrated that the expression of CD147 could be down-regulated specifically and

A

L1

L2

L3

L4

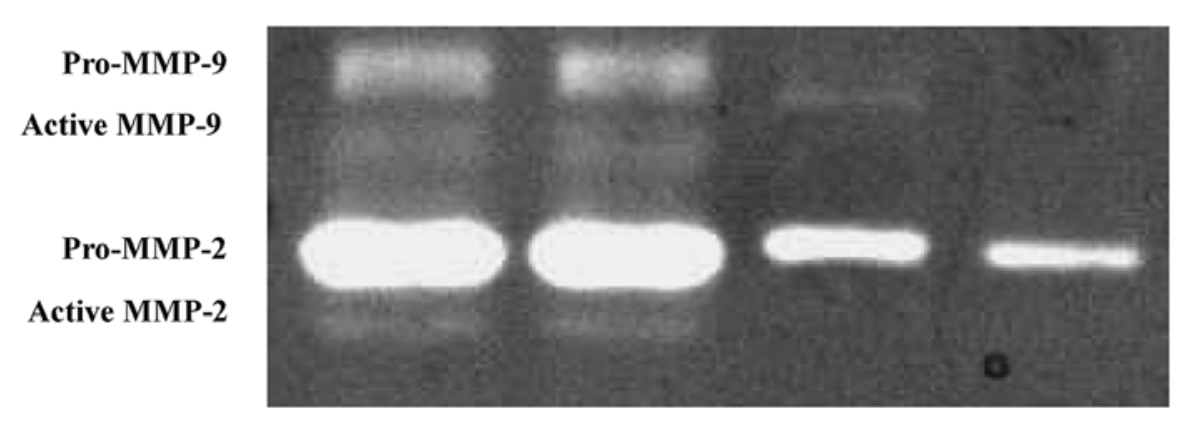

\section{L1: Hep2}

L3: Hep2/shRNA1

\section{L2: Hep2/shRNA-control}

L4: Hep2/shRNA2
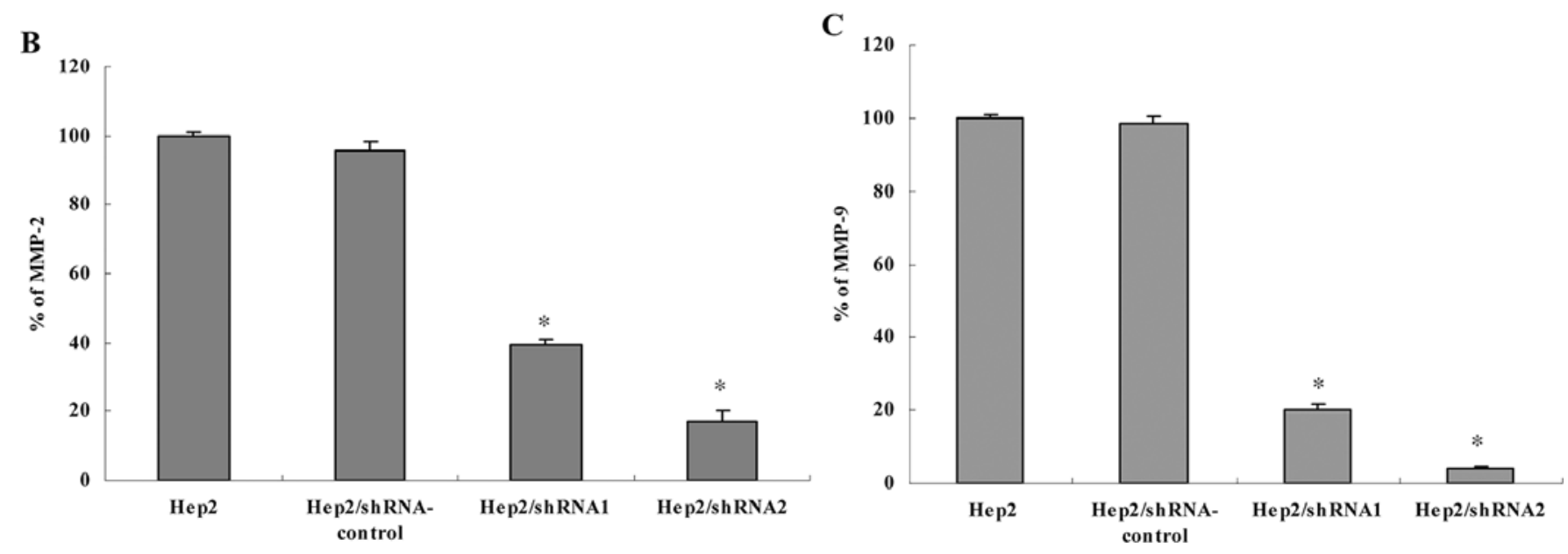

Figure 3. Gelatin zymography analysis of MMP-2 and MMP-9 activity in laryngeal carcinoma cells. Cells were incubated for 24 h and conditioned media were used for the measurement of MMP-2 and MMP-9 protein levels by gelatin zymography. (A) Photographs of the pro-MMP-2, active MMP-2 and pro-MMP-9, active MMP-9 bands, which are representative of three independent experiments, are shown. (B) Quantitative analysis of the pro-MMP-2 bands. ${ }^{*} \mathrm{P}<0.01$ compared with Hep2. (C) Quantitative analysis of the pro-MMP-9 bands. ${ }^{*} \mathrm{P}<0.01$ compared with Hep2. 
A
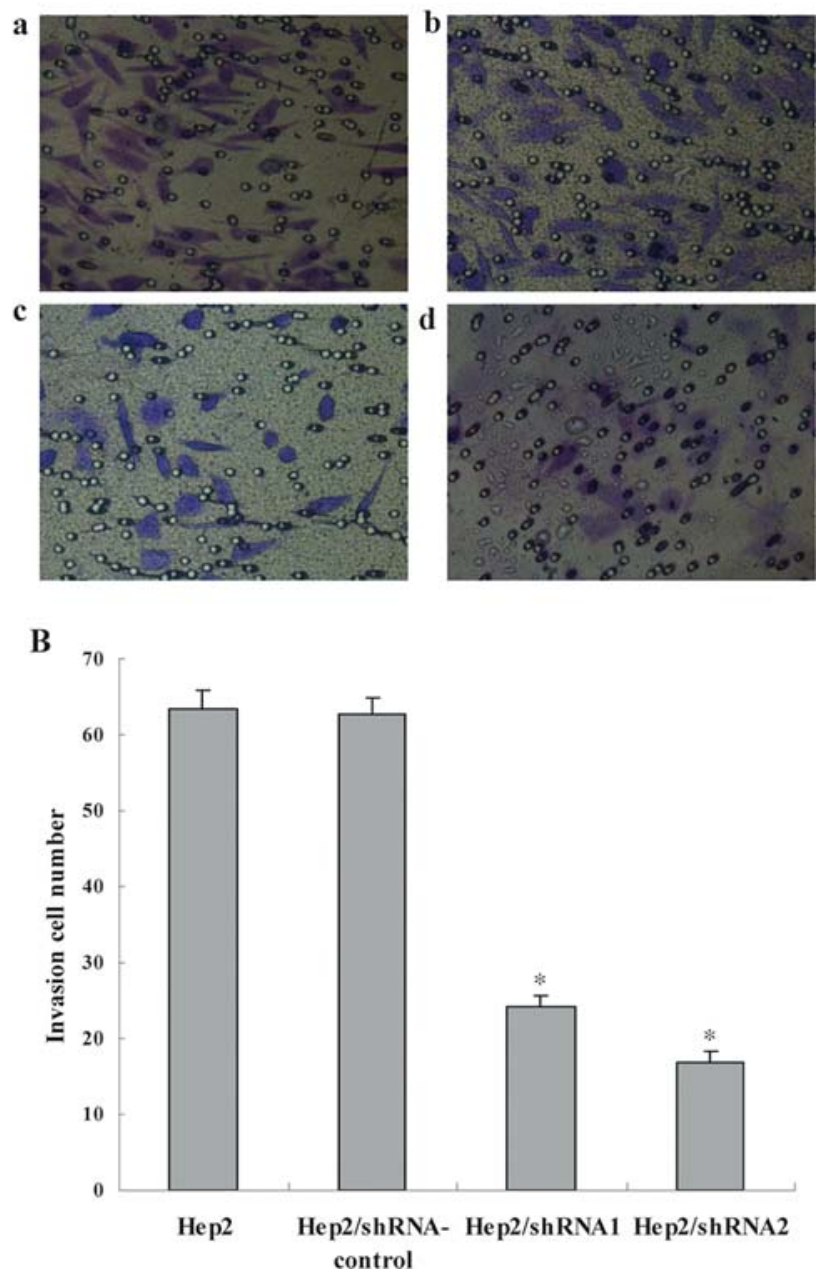

Figure 4. Effects of CD147 specific shRNAs on Matrigel invasion of Hep2 cells. (A) (a) Hep2; (b) Hep2/CD147 shRNA-control; (c) Hep2/CD147 shRNA1; (d) Hep2/CD147 shRNA2 (x400). (B) Number of cells migrated was evaluated in three fields for each experimental group and averaged. The average invaded cell number of the groups Hep2, Hep2/CD147shRNAcontrol, Hep2/CD147shRNA1 and Hep2/CD147shRNA2 was (63.37 \pm 2.53$)$, $(62.59 \pm 2.27),(24.21 \pm 1.36)$ and $(16.74 \pm 1.58)$ respectively. Compared with Hep2, the cell invasiveness of Hep2/CD147shRNA1 and Hep2/CD147 shRNA2 was reduced by 38.20 and $26.41 \%$, respectively ${ }^{*} \mathrm{P}<0.01$.

effectively by specific CD147 shRNA. The LG-CD147 (lowly glycosylated form, $\sim 33 \mathrm{kDa}$ ) completely disappeared, and the level of HG-CD147 (highly glycosylated form, 40-60 kDa) was greatly diminished.

CD147 silencing reduces the proliferation of Hep2 cells. Next, we determined the proliferation of Hep2, Hep2/shRNAcontrol, Hep2/shRNA1 and Hep2/shRNA2, respectively. As shown in Fig. 2, compared with Hep2, the proliferation of Hep2/shRNA1 and Hep2/shRNA2 was inhibited to $77.34 \%$ $(\mathrm{P}<0.01), 70.43 \%(\mathrm{P}<0.01), 62.99 \%(\mathrm{P}<0.01)$ and $73.76 \%$ $(\mathrm{P}<0.01) 67.49 \%(\mathrm{P}<0.01) 61.37 \%(\mathrm{P}<0.01)$ at 72,96 and $120 \mathrm{~h}$, respectively. There was no significant difference between Hep2/shRNA-control and Hep2 $(\mathrm{P}<0.05)$.

CD147 silencing reduces MMP-2 and MMP-9 activities in Hep2 cells. Since MMP-2 and MMP-9 play a critical role in tumor cell invasion, we examined the effect of CD147

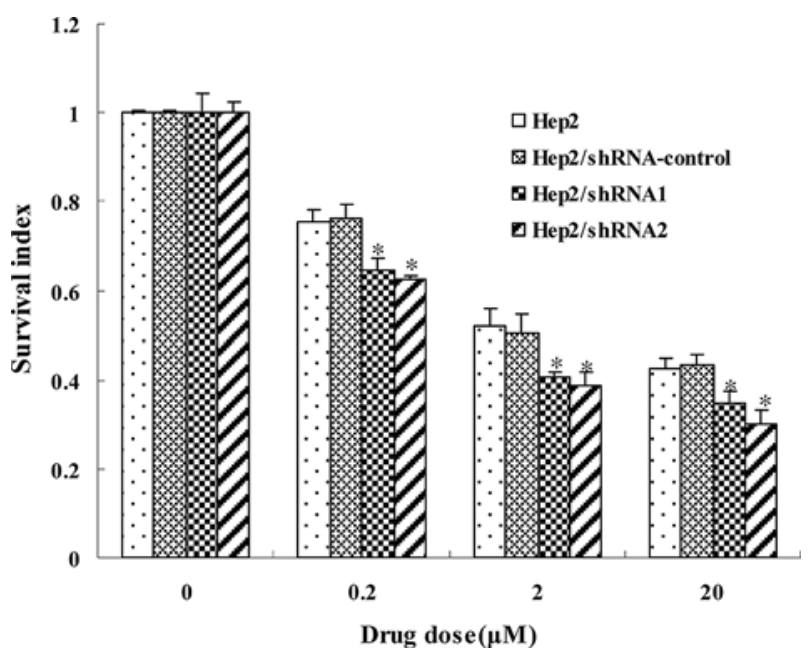

Figure 5. Effects of CD147 specific shRNAs on cisplatin sensitivity of Hep2 cells. Hep2, Hep2/CD147shRNA-control, Hep2/CD147shRNA1 and Hep2/CD147shRNA2 were treated with various concentrations of cisplatin. Cell viability was determined by MTT assay. Cell survival index

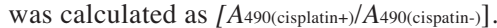

silencing on the enzyme activities of MMP-2 and MMP-9 using gelatin zymography. The gelatinolytic activities of both MMP-2 and MMP-9 were found to be reduced in Hep2/shRNA1 and Hep2/shRNA2 ( $<<0.01)$ (Fig. 3). There was no significant difference between Hep2/shRNA-control and Hep2 $(\mathrm{P}<0.05)$.

CD147 silencing reduces the invasive ability of Hep2 cells in vitro. To examine whether the down-regulation of CD147 in Hep2 affected its invasive ability, we performed an in vitro Matrigel Transwell analysis. The results showed that Hep2 and Hep2/shRNA-control cells had a similar ability to pass through the Matrigel coated filter, because the numbers of invading cells were roughly equal (Fig. 4). The number of Hep2/shRNA1 cells $(24.21 \pm 1.36, \mathrm{P}<0.01)$ and Hep2/ shRNA2 cells $(16.74 \pm 1.58, \mathrm{P}<0.01)$ passing through the Matrigel was markedly lower than the numbers of Hep2 $(63.37 \pm 2.53)$ and Hep2/shRNA-control $(62.59 \pm 2.27)$ cells.

Silencing of CD147 in Hep2 cells resulted in increased chemosensitivity to cisplatin. CD147 was found to be overexpressed in multidrug resistance tumor cells and could confer resistance to some anti-tumor drugs. We next investigated whether inhibition of CD147 by RNAi affected the sensitivity of Hep2 cells to the anti-tumor drug cisplatin. As shown in Fig. 5, the chemosensitivity in Hep2/shRNA1 and Hep2/shRNA2 was markedly reduced at all concentrations examined compared with Hep2 $(\mathrm{P}<0.01)$. There was no significant difference between Hep2/shRNA-control and Hep2 $(\mathrm{P}<0.05)$.

Tumor formation in vivo. After cell inoculation into nude mice for 28 days, the transplanted tumors were excised and their volume was calculated. In mice inoculated with Hep2/shRNA1 and Hep2/shRNA2, the tumor volume was 
A

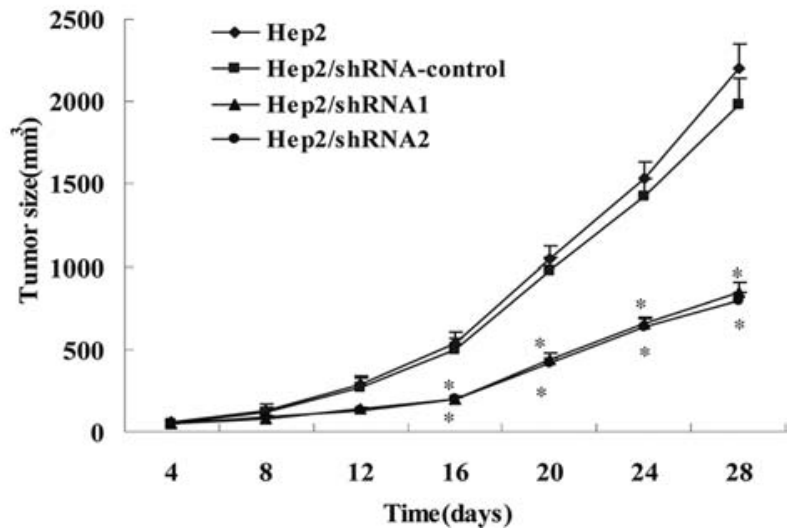

B
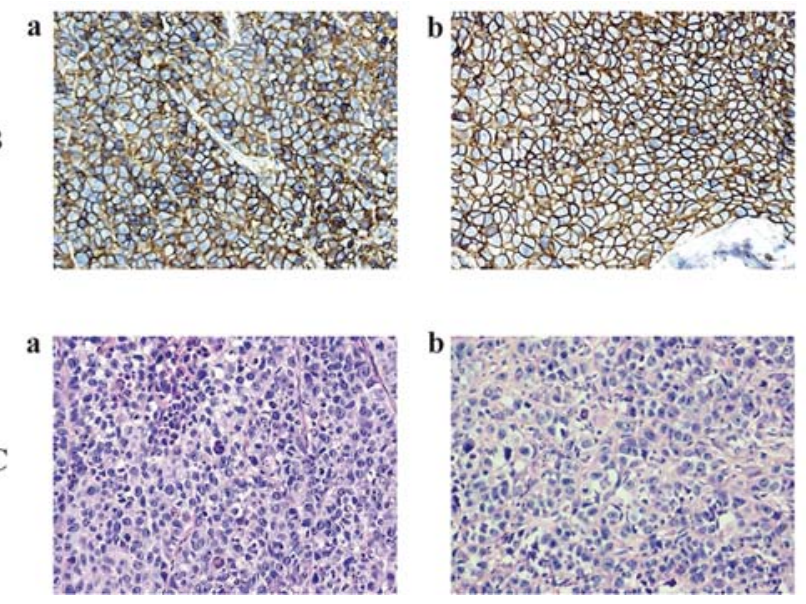

Figure 6. Effects of CD147 specific shRNAs on tumor formation in vivo and the expression of CD147 in tumor tissues. (A) Hep2, Hep2/CD147shRNAcontrol, Hep2/CD147shRNA1, Hep2/CD147shRNA2 cells were inoculated subcutaneously into the nude mice. Tumor growth was monitored and tumor volumes were calculated. ${ }^{*} \mathrm{P}<0.01$, compared with Hep2 or Hep2/CD147 shRNA-control. (B) CD147 protein expression was determined by immunohistochemistry staining in solid tumors derived from tumor tissues. (a) Hep2; (b) Hep2/CD147shRNA-control; (c) Hep2/CD147shRNA1; (d) Hep2/ CD147shRNA2 cells (x400). Differences in CD147 protein expression are shown. The data were obtained from three independent experiments. (C) Histological analysis was performed in implanted tumors with H\&E staining. (a) Hep2; (b) Hep2/CD147shRNA-control; (c) Hep2/CD147 shRNA1; (d) Hep2/CD147shRNA2 cells (x400).
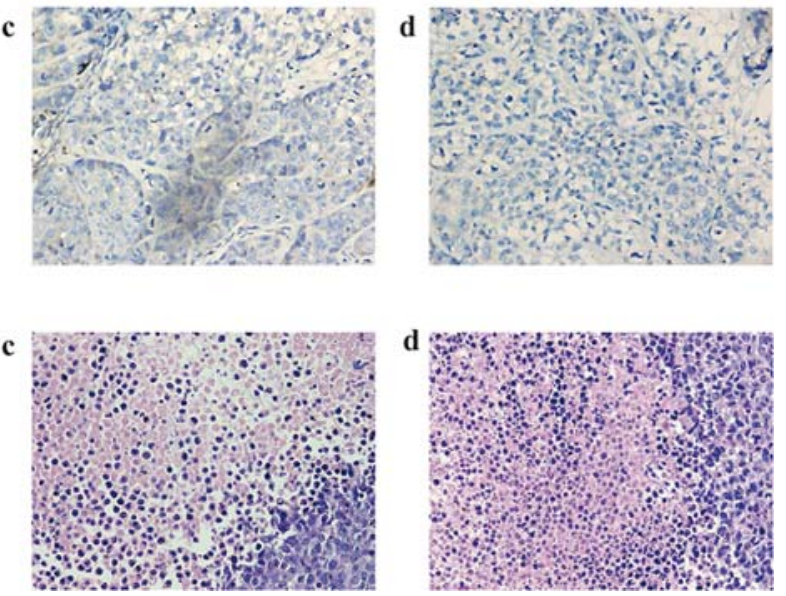

38.35 and $36.08 \%$ of that recorded for mice transplanted with Hep2 cells $(\mathrm{P}<0.01)$, respectively (Fig. 6A). Immunohistochemistry analysis showed that CD147 protein expression was almost not detectable in tumor derived from Hep2/ shRNA1 and Hep2/shRNA2 cells, but was highly expressed in tumor derived from Hep2/shRNA-control and Hep2 (Fig. 6B). Histological examination did not reveal obvious morphological changes between the tumors generated from the 4 groups, but there were larger areas of necrosis in the tumors formed by injecting with Hep2/shRNA1 and Hep2/ shRNA2 cells (Fig. 6C).

\section{Discussion}

CD147 is a transmembrane glycoprotein that is overexpressed in various types of tumors and known to possess multiple functions, such as inducing angiogenesis via stimulating VEGF production (21), promoting invasiveness via stimulating of matrix metalloproteinase production (22), interacting with certain lactate transporters (MCT1 and MCT4) and facilitating their expression on the cell surface (23) and mediating multidrug resistance via hyaluronanmediated up-regulation of ErbB2 signaling and cell survival pathway activities $(24,25)$. Recently, Qian et al showed that down-regulation of CD147 leads to some cytoskeletal gene alteration (26). Whereby the mechanism of these numerous phenomena are not yet known, it is clear that CD147 is a major mediator of malignant cell behavior.

It has been reported that CD147 is enriched on laryngeal carcinoma cells as well as on other tumor cells $(6,7)$, but the molecular mechanisms involved and the role of CD147 in laryngeal carcinoma, however, remain poorly understood. In the present study, we used RNAi technology to construct the CD147 shRNA expression vector pSilencer-shRNA for transfection into the laryngeal carcinoma cell line Hep2. We have established two stable Hep2/shRNA1 Hep2/shRNA2 clones that effectively and stably inhibited CD147 mRNA expression. Hep2/shRNA1 and Hep2/shRNA2 both significantly reduced CD147 mRNA and protein levels.

As shown in the present study, the proliferation of the Hep2 cells in which the CD147 gene has been knocked down is suppressed compared with that of the control Hep2 cells. Li et al (27) indicated that exogenous cyclophilin A promotes pancreatic cancer cell growth, which may be mediated through the interaction with CD147 and the activation of ERK1/2 and p38 mitogen-activated protein kinases. $\mathrm{Xu}$ and Hemler (28) showed a strong association between cell proliferation and the CD147-CD98 cell surface supercomplex which plays a critical role in energy metabolism. Su et al suggest that CD147, by its close association with MCT1 and 4, plays a pivotal role in the glycolysis reflected by the transmembrane transport of lactate and the regulation of cell proliferation (29). However, inconsistent with the present results, Zou et al showed that inhibition of CD147 in HO-8910pm cells had no effect on cellular proliferation in vitro (16). The disparity may be related to different shRNA sequence and different cell lines, and the mechanism needs further study.

Tumor cell invasion and metastasis, which is the main cause of treatment failure and mortality in patients, requires 
degradation of ECM mainly by MMPs $(21,30)$. MMPs, a family of enzymes that degrade various components of the extracellular matrix, play important roles in tissue remolding, tumor invasion, and metastasis $(31,32)$. Previous studies have revealed that the majority of MMPs are produced by stromal cells surrounding the tumor rather than by the tumor cells themselves $(33,34)$. An increasing body of evidence, however, suggests that MMP synthesis is stimulated by tumor cells in a paracrine fashion (35). This stimulation is at least partially attributed to CD147, Zucker reported in an animal experiment that human breast cancer cell line MDA-MB436 transfected by CD147 cDNA was more tumorigenic and invasive than non-transfected control cells, which was associated with increased expression of the MMP-2 and MMP-9 (12). In the present study, gelatin zymography demonstrated that secretions of MMP-2 and MMP-9 were markedly inhibited as CD147 protein expression was reduced via RNAi, Matrigel invasion assay indicated that invasion of Hep2/shRNA1 and Hep2/shRNA2 cells was inhibited significantly. Nude mouse experiments suggested that inhibition of CD147 expression reduces tumor cell tumorigenicity. Immunohistochemical staining showed that CD147 protein expression was very slightly detected in tumor derived from Hep2/shRNA1 and Hep2/shRNA2 cells. All the results confirm that shRNA targeting CD147 interfered with translation and expression of CD147, weakened the productions of MMPs, and inhibited the invasion of Hep2 cells in vitro and in vivo.

Resistance to multiple anticancer drugs is the main cause of failure in treating malignant tumors. In cancer cells, CD147 regulates chemosensitivity to some chemotherapeutic drugs such as paclitaxel and curcumin $(16,36)$. Regulation of CD147 expression is considered to be a novel approach to overcome resistance to multiple anticancer drugs. Cisplatin is one of the most common and potent antihead and neck cancer chemotherapeutic drugs, and it has a response rate as a single agent in head and neck cancer of approximately $30 \%$, so for this investigation, we used the chemotherapeutic drug cisplatin (37). The MTT results revealed that down-regulation of CD147 also increased chemosensitivity to anti-tumor drug cisplatin in Hep2 cells. Although the biochemical mechanism of action of cisplatin remains incompletely understood, the current accepted paradigm is that the drug binds to nuclear DNA, leading to interference with normal transcription and/or DNA replication mechanisms (38).

In summary, we showed that CD147-targeting shRNA could significantly down-regulate the CD147 mRNA level in laryngeal carcinoma cells and that it inhibited their proliferation and invasive activity in vitro and in vivo. Our findings indicate that highly expressed CD147 on the surface of laryngeal carcinoma cells plays an important role in the proliferation and invasiveness of malignant melanoma. We also showed that down-regulation of CD147 confered laryngeal carcinoma cells resistance to the chemotherapeutic drug cisplatin. Our findings indicated that CD147 might be a potential target for therapeutic anticancer drugs and provide new insights into the development of gene therapy technology to treat patients with laryngeal carcinoma.

\section{Acknowledgements}

This study was supported by National Natural Science Foundation of China (No. 30873022) and Science and Technology Development Foundation of Nanjing Medical University (No. 09NJMUM070).

\section{References}

1. Parkin DM, Pisani P and Ferlay J: Estimates of the worldwide incidency of eighteen major cancers in 1985. Int J Cancer 54: 594-606, 1993 .

2. Ferlay J, Bray F, Pisani P and Parkin DM: Cancer incidence, mortality and prevalence worldwide, version 1.0. IARC Cancer Base No. 5. IARC Press, Lyon, 2001.

3. Parker SL, Tong T, Bolden S and Wingo PA: Cancer statistics, 1996. CA Cancer J Clin 46: 5-27, 1996.

4. Ampil FL, Nathan CO, Caldito G, Lian TF, Aarstad RF and Krishnamsetty RM: Total laryngectomy and postoperative radiotherapy for T4 laryngeal cancer: a 14-year review. Am J Otolaryngol 25: 88-93, 2004.

5. Yu H, Xin YF, Duan XD, Zhu LX and Jin DJ: Dynamic analysis of epidemiology and etiology on laryngeal carcinoma. Mod Biomed Progr 3: 393-395, 2007.

6. Rosenthal EL, Shreenivas S, Peters GE, Grizzle WE, Desmond R and Gladson CL: Expression of extracellular matrix metalloprotease inducer in laryngeal squamous cell carcinoma. Laryngoscope 113: 1406-1410, 2003.

7. Hanata K, Yamaguchi N, Yoshikawa K, et al: Soluble EMMPRIN (extra-cellular matrix metalloproteinase inducer) stimulates the migration of HEp-2 human laryngeal carcinoma cells, accompanied by increased MMP-2 production in fibroblasts. Arch Histol Cytol 70: 267-277, 2007

8. Shinsuke S, Mitsuru S, Haruki S and Kazuo I: Direct cell-cell interaction enhances pro-MMP-2 production and activation in co-culture of laryngeal cancer cells and fibroblasts: involvement of EMMPRIN and MT1-MMP. Exp Cell Res 293: 259-266, 2004.

9. Sameshima T, Nabeshima K, Toole BP, et al: Expression of emmprin (CD147), a cell surface inducer of matrix metalloproteinases, in normal human brain and gliomas. Int $\mathrm{J}$ Cancer 88: 21-27, 2000.

10. Kanekura T, Chen X and Kanzaki T: Basigin (CD147) is expressed on melanoma cells and induces tumor cell invasion by stimulating production of matrix metalloproteinases by fibroblasts. Int J Cancer 99: 520-528, 2002.

11. Jiang JL, Zhou Q, Yu MK, Ho LS, Chen ZN and Chan HC: The involvement of $\mathrm{HAb} 18 \mathrm{G} / \mathrm{CD} 147$ in regulation of store-operated calcium entry and metastasis of human hepatoma cells. J Biol Chem 276: 46870-46877, 2001.

12. Zucker S, Hymowitz M, Rollo EE, et al: Tumorigenic potential of extracellular matrix metalloproteinase inducer. Am J Pathol 158: 1921-1928, 2001 .

13. Reimers N, Zafrakas K, Assmann V, et al: Expression of extracellular matrix metalloproteases inducer on micrometastatic and primary mammary carcinoma cells. Clin Cancer Res 10: 3422-3428, 2004.

14. Iacono KT, Brown AL, Greene MI and Saouaf SJ: CD147 immunoglobulin superfamily receptor function and role in pathology. Exp Mol Pathol 83: 283-295, 2007.

15. Nelson AR, Fingleton B, Rothenberg ML and Matrisian LM: Matrix metalloproteinases: biologic activity and clinical implications. J Clin Oncol 18: 1135-1149, 2000.

16. Zou W, Yang H, Hou X, Zhang W, Chen B and Xin X: Inhibition of CD147 gene expression via RNA interference reduces tumor cell invasion, tumorigenicity and increases chemosensitivity to paclitaxel in HO-8910pm cells. Cancer Lett 248: 211-218, 2007.

17. Tang Y: Regulation of vascular endothelial growth factor expression by EMMPRIN via the PI3K-Akt signaling pathway. Mol Cancer Res 4: 371-377, 2006.

18. Yurchenko V, O'Connor M, Dai WW, Guo H, Toole B, Sherry B and Bukrinsky M: CD147 is a signaling receptor for cyclophilin B. Biochem Biophys Res Commun 288: 786-788, 2001.

19. Tang W, Chang S and BandHemler ME: Links between CD147 function, glycosylation, and caveolin-1. Mol Biol Cell 15: 4043-4050, 2004 
20. Chen X, Lin J, Kanekura T, et al: A small interfering CD147targeting RNA inhibited the proliferation, invasiveness, and metastatic activity of malignant melanoma. Cancer Res 66: 11323-11330, 2006.

21. Tang Y, Nakada MT, Kesavan P, et al: Extracellular matrix metalloproteinase inducer stimulates tumor angiogenesis by elevating vascular endothelial cell growth factor and matrix metalloproteinases. Cancer Res 65: 3193-3199, 2005.

22. Marieb EA, Zoltan-Jones A, Li R, et al: Emmprin promotes anchorage-independent growth in human mammary carcinoma cells by stimulating hyaluronan production. Cancer Res 64 : 1229-1232, 2004.

23. Kirk P, Wilson MC, Heddle C, Brown MH, Barclay AN and Halestrap AP: CD147 is tightly associated with lactate transporters MCT1 and MCT4 and facilitates their cell surface expression. EMBO J 19: 3896-3904, 2000.

24. Misra S: Regulation of multidrug resistance in cancer cells by hyaluronan. J Biol Chem 278: 25285-25288, 2003.

25. Toole BP: Hyaluronan: from extracellular glue to pericellular cue. Nat Rev Cancer 4: 528-539, 2004.

26. Qian AR, Wei Z, Cao JP, et al: Downregulation of CD147 expression alters cytoskeleton architecture and inhibits gelatinase production and SAPK pathway in human hepatocellular carcinoma cells. J Exp Clin Cancer Res 27: 50, 2008.

27. Min L, Qihui Z, Uddalak B, et al: Cyclophilin A is overexpressed in human pancreatic cancer cells and stimulates cell proliferation through CD147. Cancer 106: 2284-2294, 2006.

28. Xu D and Hemler ME: Metabolic activation-related CD147CD98 complex. Mol Cell Proteomics 4: 1061-1071, 2005.

29. Su J, Chen X and Kanekura T: A CD147-targeting siRNA inhibits the proliferation, invasiveness, and VEGF production of human malignant melanoma cells by down-regulating glycolysis. Cancer Lett 273: 140-147, 2009.
30. Li HG, Xie DR, Shen XM, Li HH, Zeng H and Zeng YJ: Clinicopathological significance of expression of paxillin, syndecan-1 and EMMPRIN in hepatocellular carcinoma. World J Gastroenterol 11: 1445-1451, 2005.

31. MacDougall JR, Bani MR, Lin Y, Rak J and Kerbel RS: The 92-kDa gelatinase B is expressed by advanced stage melanoma cells: suppression by somatic cell hybridization with early stage melanoma cells. Cancer Res 55: 4174-4181, 1995.

32. Murray GI, Duncan ME, O'Neil P, McKay JA, Melvin WT and Fothergill JE: Matrix metalloproteinase-1 is associated with poor prognosis in oesophageal cancer. J Pathol 185: 256-261, 1998.

33. Cheng MF, Tzao C, Tsai WC, et al: Expression of EMMPRIN and matriptase in esophageal squamous cell carcinoma: correlation with clinicopathological parameters. Dis Esophagus 19: 482-486, 2006.

34. Lee J, Yongsong S, Choi J, et al: Increased expression of matriptase is associated with histopathologic grades of cervical neoplasia. Human Pathol 36: 626-633, 2005.

35. Han ZD, He HC, Bi XC, et al: Expression and clinical significance of CD147 in genitourinary carcinomas. J Surg Res 160: 260-267, 2010.

36. Jia L, Wang H, Qu S, Miao X and Zhang J: CD147 regulates vascular endothelial growth factor-A expression, tumorigenicity, and chemosensitivity to curcumin in hepatocellular carcinoma. IUBMB Life 60: 57-63, 2008.

37. Higham P, Quek S and Cohen HV: Dental management for head and neck cancer patients undergoing radiation therapy: comprehensive patient based planning, a case report. JNJ Dent Assoc 80: 31-33, 2009.

38. Fuertes MA, Castilla J and Alonso CandPerez JM: Cisplatin biochemical mechanism of action: from cytotoxicity to induction of cell death through interconnections between apoptotic and necrotic pathways. Curr Med Chem 10: 257-266, 2003. 